\begin{tabular}{c|l|l|l}
$\begin{array}{c}\text { Case Reports in } \\
\text { Oncology }\end{array}$ & $\begin{array}{l}\text { Case Rep Oncol 2010;3:428-433 } \\
\text { DOI: 10.1159/000322204 }\end{array}$ & $\begin{array}{l}\text { Published online: } \\
\text { November 24, 2010 }\end{array}$ & $\begin{array}{l}\text { O 2010 S. Karger AG, Basel } \\
\text { ISSN 1662-6575 } \\
\text { www.karger.com/cro }\end{array}$ \\
\hline
\end{tabular}

This is an Open Access article licensed under the terms of the Creative Commons AttributionNonCommercial-NoDerivs 3.0 License (www.karger.com/OA-license), applicable to the online version of the article only. Distribution for non-commercial purposes only.

\title{
One-Step Laparoscopic Management of a Female Adnexal Tumor of Wolffian Origin
}

\author{
R. Seracchioli ${ }^{a}$ M. Mabrouk ${ }^{a, c} \quad$ S. Solfrini ${ }^{a} \quad$ S. Savelli ${ }^{a}$ \\ G. Caprarab C. Facchini ${ }^{\mathrm{a}} \quad$ E. Geraci ${ }^{\mathrm{a}} \quad$ S. Del Forno ${ }^{\mathrm{a}}$ \\ S. Venturolia
}

aMinimally Invasive Gynecological Surgery Center, Gynecology and Reproductive Medicine Unit, and bepartment of Pathology, S. Orsola-Malpighi Hospital, University of Bologna, Bologna, Italy; 'Department of Obstetrics and Gynecology, Alexandria University, Alexandria, Egypt

\section{Key Words}

Adnexal mass · Frozen sections · Gynecological oncology · Laparoscopy · Minimally invasive approach · Ultrasound · Wolffian tumor

\begin{abstract}
We report a case of female adnexal tumor of Wolffian origin (FATWO), a rare neoplasm arising from the mesonephric ducts. A 48-year-old woman came first to our center for a recent discovery of a pelvic mass. Transvaginal ultrasonographic findings suggested a solid right para-ovarian mass suspected to be malignant. After thorough counseling, the patient underwent operative laparoscopy for excision of the para-ovarian mass with frozen section (FS) examination resulting in the diagnosis of a poorly differentiated adenocarcinoma. In this case, FS results allowed performing a comprehensive oncological staging, through a totally laparoscopic extrafascial hysterectomy, bilateral adnexectomy, total omentectomy, pelvic wall peritonectomy, and pelvic, parasacral and para-aortic lymphadenectomy. Final pathological and immunohistochemical results confirmed the diagnosis of FATWO. To our knowledge, this is the first case of FATWO managed entirely by a minimally invasive laparoscopic approach in a single surgical session.
\end{abstract}

\section{Introduction}

Female adnexal tumors of Wolffian origin (FATWOs) were first reported in 1973 by Kariminejad and Scully [1]. This rare neoplasm usually arises from the remnants of the 
mesonephric ducts, occurring in the broad ligament, mesosalpinx, fallopian tube, ovary and peritoneum $[2,3]$. The vast majority of cases reported in the literature are considered to have a low malignant potential, although in some instances a more aggressive behavior is encountered, with a tendency to distant metastases and recurrence $[4,5]$. Preoperative diagnosis of FATWO is very difficult because of the rarity of the disease and the limited literature available. There are no comprehensible recommendations regarding its preoperative workup and optimal management [2].

Data on this tumor derive from few cases reported in the literature [1-9]. Despite the heterogeneity in management, the surgical approach remained the mainstay of treatment by means of total abdominal hysterectomy with bilateral salpingo-oophorectomy. In almost all cases, patients underwent first surgery and were subsequently submitted to a second intervention after the final histological diagnosis $[5,6]$.

We report a case of FATWO in which the suspicion of a para-ovarian malignancy was raised preoperatively during transvaginal ultrasonography. After proper counseling of the management plans, the patient was treated in a single surgical session through a comprehensive oncological staging, entirely performed by laparoscopy, following the histological indications of frozen section (FS) examination.

\section{Case Report}

A 48-year-old nulliparous woman was referred to our center for a recent discovery of a pelvic mass. She was completely asymptomatic. Her previous clinical history was significant for a mini-laparotomic appendectomy and nodulectomy of a breast fibroadenoma. Pelvic transvaginal and transabdominal ultrasound revealed an enlarged uterus, with a non-homogeneous myometrial structure due to fibromatosis and two small uterine myomas. The endometrial layer was regular. The ovaries were both normal for size and echostructure. The transvaginal, high-frequency ultrasound scan revealed a solid right, para-ovarian mass, with irregular external profiles and internal hyperechoic spots that measured $50 \mathrm{~mm}$ in diameter. This solid mass presented good cleavage planes with surrounding tissues and clear 'sliding' signs with the uterus and both ovaries. The vascular pattern was homogenous with a 3-color score at power Doppler. These sonographic findings suggested a right para-ovarian malignancy. The transabdominal ultrasound exploration of pelvic and abdominal peritoneum showed neither peritoneal implants nor free fluid or other masses.

The patient was recommended to undergo MRI examination of the pelvis that confirmed the presence and the anatomical location of the mass. A chest X-ray was unremarkable, serum CA-125 and other tumor markers were negative.

After a detailed explanation and comprehensive counseling about the advantages of a single surgical intervention, the patient was scheduled for operative laparoscopy for excision of the para-ovarian mass with FS examination. The patient was also fully informed about the surgical plans according to the FS outcomes or to laparoscopic findings. A written informed consent was obtained.

After the induction of general anesthesia and endotracheal intubation, the patient was placed in the dorsal lithotomy position. Pneumoperitoneum was created using an open laparoscopy trocar at the level of the umbilicus, through which a $10-\mathrm{mm}$ scope was placed. Two further 5 -mm trocars were introduced under direct view: one was positioned lateral to the right inferior epigastric artery above the anterior superior iliac spine and one suprapubically. Two other $12-\mathrm{mm}$ trocars were placed, one lateral to the left inferior epigastric artery and one above the umbilicus before the para-aortic lymphadenectomy.

At the diagnostic laparoscopy, we found a $50-\mathrm{mm}$ right para-ovarian mass located in the pouch of Douglas with irregular cauliflower surface, increased superficial vascularization and good cleavage plane with surrounding tissue (fig. 1). The mass was attached by a pedicle to the fimbrial part of the right tube. Both ovaries were normal for site, size and structure. On the peritoneum of the Douglas pouch, 
there were some clear vesicles about $5 \mathrm{~mm}$ each. Other abdominal organs and the remnant peritoneum were normal without macroscopically visible lesions. No ascitic fluid was found.

A sample of fluid from peritoneal washing was collected and sent for cytological examination, which demonstrated the presence of epithelial neoplastic cells. Subsequently, the para-ovarian mass was accurately excised avoiding spillage, removing it from the pelvis with an endo bag through a lateral mini-laparotomic incision and sent for FS examination, which revealed a poorly differentiated adenocarcinoma. Subsequently, we performed a laparoscopic bilateral adnexectomy and both adnexa were diagnosed as free from disease following FS examination.

Based on the FS results of an unspecified para-ovarian adenocarcinoma with both adnexa unaffected, it has been decided to perform comprehensive staging through a totally laparoscopic extrafascial hysterectomy using a vaginal manipulator, total omentectomy and pelvic wall peritonectomy together with pelvic, parasacral and para-aortic lymphadenectomy. Total operative time was $4 \mathrm{~h}$ and $15 \mathrm{~min}$. There was no evidence of macroscopic disease at the end of the surgery. There were no intraoperative complications. The postoperative course was uneventful and the patient was discharged on postoperative day 6 .

The final histological examination revealed a well-capsulated mass that measured $6 \times 5 \times 2 \mathrm{~cm}$ in diameter, which was located in the right broad ligament and attached to the right fallopian tube. The cut section of the mass showed a circumscribed, solid tissue without apparent cystic areas. Pathologic examination revealed a tumor composed of sheets of polygonal cells with fairly monomorphic nuclei, dispersed chromatin and conspicuous nucleoli. The tumor showed different histological patterns, including a reticular, sieve-like appearance, tubule, dilated cystic structures and islands of cells peripheral to glandular spaces with eosinophilic secretions. Immunohistochemically, the tumor was strongly positive for vimentin, calretinin, inhibin and pan-cytokeratin (MNF 116; fig. 2, fig. 3); CK7 and chromogranin were negative. Ovaries, fallopian tubes, uterus, omentum and pelvic peritoneum were macroscopically and histologically unremarkable. A total of 32 pelvic and 24 aortic nodes were collected, all of them were negative for neoplastic infiltration. Based on pathological and immunohistochemical results, the diagnosis of FATWO has been confirmed [7-9]. The pathological specimens of the adnexal mass were also reviewed by the National Institute of Tumor in Milan that confirmed the diagnosis.

During a multidisciplinary oncological group meeting, together with oncologists and radiotherapists, considering the intraoperative and pathological findings, it was decided not to recommend the patient postoperative therapy. As the surgical staging was complete and the tumor did not show aggressive clinical or histopathological features, the patient was scheduled for clinical and instrumental follow-up. The patient currently continues the follow-up, and 1 year after surgery she is asymptomatic and her clinical and laboratory findings are unremarkable, with no signs of relapse.

\section{Discussion}

In the case reported, para-ovarian malignancy was suspected preoperatively using transvaginal ultrasonography. Para-ovarian cysts represent up to $20 \%$ of adnexal masses, and sonographic features of these cysts were well described by Savelli et al.[10] and Smorgick et al. [11]. The diagnosis of these cysts is feasible based on a transvaginal scan by investigating the presence of the 'split sign' between ovaries and the cyst. The majority of para-ovarian cysts are unilocular simple cysts with an anechoic content and low potential of malignancy. However, the presence of papillary projections and solid parts, described in about $30 \%$ of cases, can change the risk of malignancy and the subsequent management of ovarian masses [12-14]. An accurate ultrasound detecting a new-onset para-ovarian solid mass with internal hyperechoic pattern and high vascularization helps to define the preoperative risk of malignancy for the patient and to plan the surgical intervention after proper counseling. 


\begin{tabular}{|c|c|c|c|}
\hline $\begin{array}{l}\text { Case Reports in } \\
\text { Oncolocy }\end{array}$ & $\begin{array}{l}\text { Case Rep Oncol 2010;3:428-433 } \\
\text { DOI: } 10.1159 / 000322204\end{array}$ & \begin{tabular}{|l} 
Published online: \\
November 24, 2010
\end{tabular} & $\begin{array}{l}\text { ( ) } 2010 \text { S. Karger AG, Basel } \\
\text { ISSN } 1662-6575 \\
\text { www.karger.com/cro }\end{array}$ \\
\hline
\end{tabular}

The surgical approach is reported as the mainstay of treatment for FATWOs. Previous authors concluded that tumor debulking with hysterectomy and bilateral adnexectomy is the most successful treatment, because relapses often occur in patients initially treated only with conservative procedures such as cystectomy or tumor enucleation [3-6]. Few cases also requested a second surgery to complete staging after the final histological diagnosis of FATWO $[5,6]$.

Laparoscopy is currently an acceptable surgical approach in the management of adnexal masses [13]. In our case, the intraoperative laparoscopy confirmed ultrasound findings. During the laparoscopic approach for suspected adnexal malignancy, it is highly recommended to avoid the intraperitoneal rupture of the mass, removing it completely through an endoscopic bag and possibly a mini-laparotomic incision to preserve the capsular integrity $[14,15]$.

To our knowledge, all reported cases of FATWO were treated by laparotomy, except one reported by Handa et al. [5] treated with laparoscopic-assisted vaginal hysterectomy.

Intraoperative FS examination is important to guide the surgical management in case of suspected adnexal malignancy, because it may assess the nature of the disease and determine tumor spread. In our case, FS results facilitated complete surgery in a single session, avoiding the risks associated with a second intervention. Comprehensive surgical staging was carried out in a single step through a laparoscopic minimally invasive approach with adequate oncological radicality and complete cytoreduction after surgery, resulting in a low risk of morbidity, a short hospital stay and fast return to full activity.

In conclusion, we underline the importance to refer patients with suspicion of adnexal malignancy to a highly specialized center, in which sonographers, surgeons and pathologists are dedicated to the management of gynecological oncology.

\section{Disclosure Statement}

There is no conflict of interest. 


\begin{tabular}{r|l|l|l}
$\begin{array}{c}\text { Case Reports in } \\
\text { Oncology }\end{array}$ & $\begin{array}{l}\text { Case Rep Oncol 2010;3:428-433 } \\
\text { DOl: 10.1159/000322204 }\end{array}$ & $\begin{array}{l}\text { Published online: } \\
\text { November 24, 2010 }\end{array}$ & $\begin{array}{l}\text { O 2010 S. Karger AG, Basel } \\
\text { ISSN 1662-6575 } \\
\text { www.karger.com/cro }\end{array}$ \\
\hline
\end{tabular}

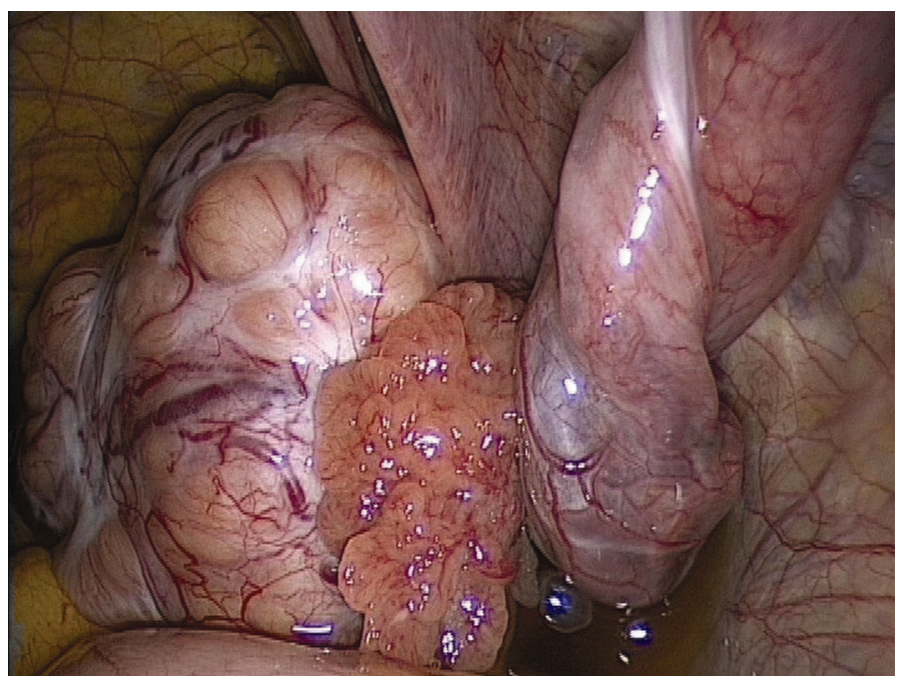

Fig. 1. Intraoperative finding of the right adnexal mass.

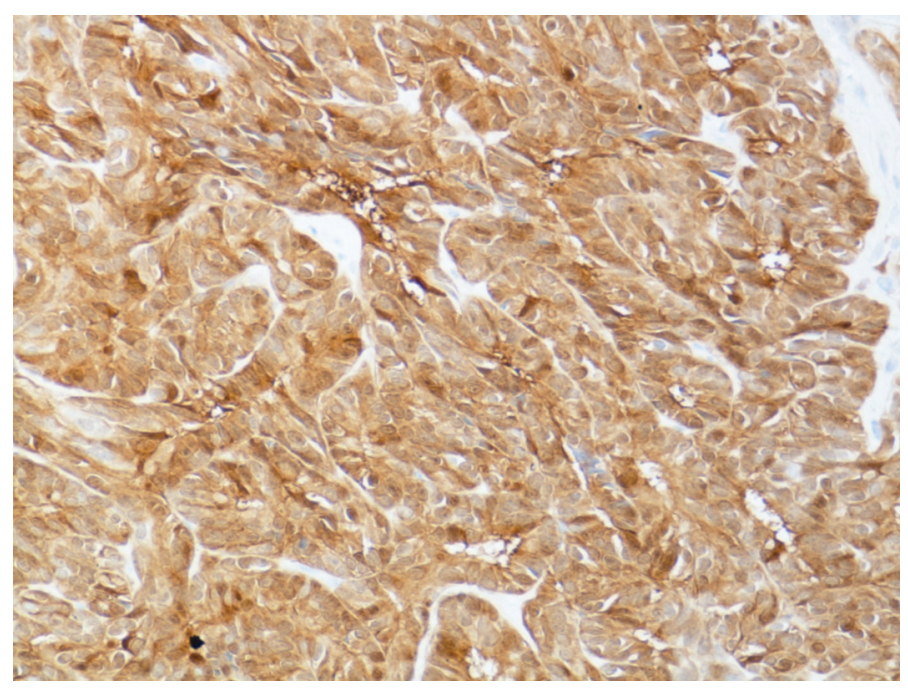

Fig. 2. Immunohistochemical staining of tumor cells was positive for cytokeratin and calretinin. 


\begin{tabular}{c|l|l|l}
$\begin{array}{c}\text { Case Reports in } \\
\text { Oncology }\end{array}$ & $\begin{array}{l}\text { Case Rep Oncol 2010;3:428-433 } \\
\text { DOI: 10.1159/000322204 }\end{array}$ & $\begin{array}{l}\text { Published online: } \\
\text { November 24, 2010 }\end{array}$ & $\begin{array}{l}\text { O 2010 S. Karger AG, Basel } \\
\text { ISSN 1662-6575 } \\
\text { www.karger.com/cro }\end{array}$ \\
\hline
\end{tabular}

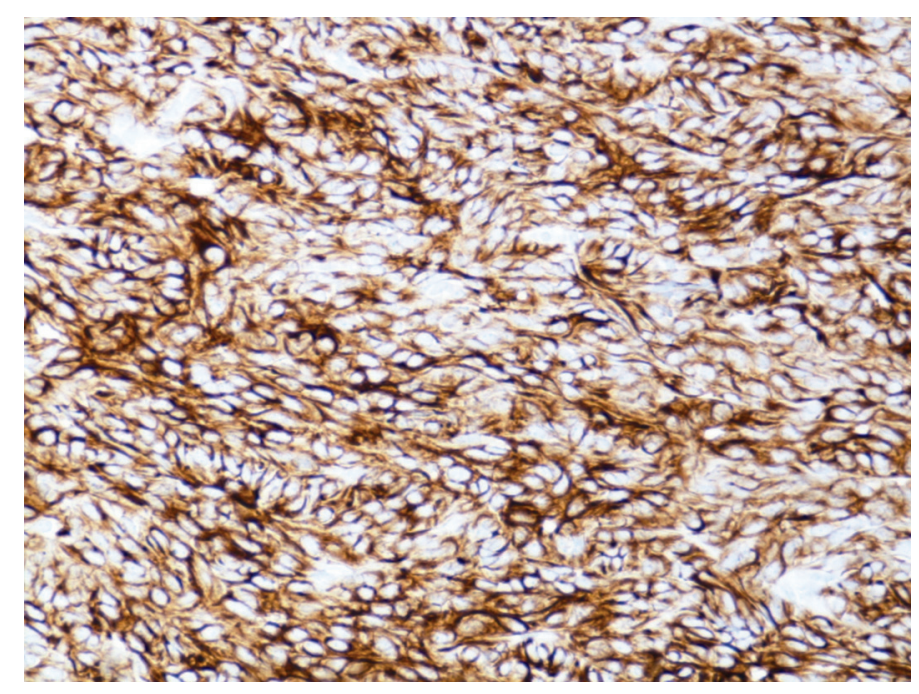

Fig. 3. Immunohistochemical staining of tumor cells was positive for cytokeratin and calretinin.

\section{References}

1 Kariminejad MH, Scully RE: Female adnexal tumor of probable Wolffian origin. Cancer 1973;31:671-677.

-2 Deen S, Duncan TJ, Hammond RH: Malignant female adnexal tumors of probable Wolffian origin. Int J Gynecol Pathol 2007;26:383-386.

3 Ramirez PT, Wolf JK, Malpica A: Woffian duct tumors: case reports and review of the literature. Gynecol Oncol 2002;86:225-230.

4 Lesin J, Forko-Ilic J, Plavec A: Management of Wolffian duct tumor recurrence without chemotherapy. Arch Gynecol Obstet 2009;280:855-857.

5 Handa Y, Kato H, Kaneuchi M: High-grade broad ligament cancer of mullerian origin: immunohistochemical analysis of a case and review of the literature. Int J Gynecol Cancer 2009;17:705-734.

6 Steed H, Oza A, Chapman WB: Female adnexal tumor of probable wolffian origin: a clinicopathological case report and a possible new treatment. Int J Gynecol Cancer 2004;14:546-550.

7 Devouassoux-Shisheboran M, Silver SA, Tavassoli FA: Wolffian adnexal tumor, so-called female adnexal tumor of probable Wolffian origin (FATWO): immunohistochemical evidence in support of a Wolffian origin. Hum Pathol 1999;30:856-863.

8 Tiltman AJ, Allard U: Female adnexal tumours of probable Wolffian origin: an immunohistochemical study comparing tumours, mesonephric remnants and paramesonephric derivatives. Histopathology 2001;38:237242 .

9 Harada O, Ota H, Takagi K: Female adnexal tumour of probable Wolffian origin: morphological, immunohistochemical and ultrastructural study with c-kit analysis. Pathol Int 2006;56:95-100.

- 10 Savelli L, Ghi T, De Iaco P: Paraovarian/paratubal cysts: comparison of transvaginal sonographic and pathological findings to establish diagnostic criteria. Ultrasound Obstet Gynecol 2006;28:330-334.

-11 Smorgick N, Herman A, Schneider D: Paraovarian cysts of neoplastic origin are underreported. JSLS 2009;13:22-26.

12 Sokalska A, Timmerman D, Testa AC: Diagnostic accuracy of transvaginal ultrasound examination for assigning a specific diagnosis to adnexal masses. Ultrasound Obstet Gynecol 2009;34:462-470.

13 Hilgher WS, Magrina JF, Magtibay PM: Laparoscopic management of the adnexal mass. Clin Obstet Gynecol 2006;49:535-548.

14 Vergote I, De Brabanter J, Fyles A: Prognostic importance of degree of differentiation and cyst rupture in stage I invasive epithelial ovarian carcinoma. Lancet 2001;357:176-182.

15 Panici PB, Palaia I, Bellati F: Laparoscopy compared with laparoscopically guided minilaparotomy for large adnexal masses: a randomized controlled trial. Obstet Gynecol 2007;110:241-248. 